\title{
Mechanical Properties Of Geopolymer Concrete: Statistical Analysis And Prediction Models
}

\author{
Ahmed Hassan', M Talha Junaid $^{2}$, Samer Barakat ${ }^{3}$ \\ University of Sharjah \\ Sharjah, UAE \\ U17105553@sharjah.ac.ae; sbarakat@sharjah.ac.ae \\ mjunaid@sharjah.ac.ae
}

\begin{abstract}
With the rise for the need of construction materials, and the considerable amount of impact the cement industry has on global warming, the use and study of alternative materials for construction has emerged on the scene. The use of alkali-activated binder, which has less of an impact on the environment due to the use of by-products of other industries such as power generation and burning coal, is on the increase with time. Despite the fact that (Alkali Activated Binder) AAB is currently in area of active research, many models for the prediction of mechanical properties are available, however they follow the OPCC methods or (template) of determining the mechanical properties of $\mathrm{AAB}$. The models available currently use only compressive strength to predict other mechanical properties, without directly addressing the chemical composition of the AAB. The main aim of this study is to provide prediction models for the mechanical properties of $\mathrm{AAB}$ and identify the parameters that affect these properties, and to determine the significance of these effects. This research will attempt to collect the data from multiple researches, study the characteristics of each work, and propose models that can describe all the data collected by regression and dimensional analysis. By analysing the collected data from over 50 published papers, with over 500 tested samples, models are generated for determining the Modulus of Elasticity, splitting strength and modulus of rupture of AAB. These models take into account the compressive strength as the most significant characteristic, while also considering the effect of test conditions and the chemical composition of the samples.
\end{abstract}

Keywords: Geopolymer Concrete, Modulus of Elasticity, splitting strength and modulus of rupture, compressive strength

\section{Introduction}

Among the most frequently used materials in construction is Portland cement. And with the increase in the population, and the constant demand for new buildings and constructions, the demand for Portland cement will only be increasing.

In this day of age, the rising concerns of environmental impact effect on the long run to maintain the prosperity of the planet introduces a major factor of what materials can be used and the procedure of manufacturing these materials (M Talha Junaid, Kayali, Khennane, \& Black, 2015). Global warming caused by the greenhouse gases such as carbon dioxide (CO2), $\mathrm{CO} 2$ contributes about $65 \%$ of global warming (Mccaffrey, 2002). Cement industry is one of the responsible of emitting $\mathrm{CO} 2$ into the atmosphere. A way to reduce the effect of cement manufacturing is using alternative materials to replace the cement in construction that does not have as a heavy carbon footprint as the Portland cement. Many alternatives surfaced to replace the Portland cement such as fly ash, silica fume, granulated blast furnace slag, rice-husk ash and metakaolin (Rangan, 2007)

Studies showed that an alkaline liquid could react with silicon and aluminum in by-products of fly ash or rice husk ash (Muhammad Talha Junaid, Khennane, \& Kayali, 2014). The chemical reaction is called a polymerization reaction process, thus this material was called a 'Geopolymer.

Alkaline liquids are created from soluble alkali metals such as Sodium and potassium. The two most commonly used alkali liquids activators are sodium hydroxide $(\mathrm{NaOH})$ and potassium hydroxide $(\mathrm{KOH})$; where sodium hydroxide is being used more due to its relatively cheaper cost.

The mixing process in order to create the Geopolymer concrete could be summarized by figure 1 below: (Nguyen, Ahn, Le, \& Lee, 2016)

Much research was done on the topic of behavior and characteristics of Geopolymer concrete over the past twenty years, and many models were proposed. However the sample size of these researches was relatively small to create reliable models to describe the majority of other samples done by other researches. Adding to that, when compared later on in this research, 
each researcher has presented a different model than others. Some comply with some sort to other model, while others do not agree. And almost all the other research done, follow the OPCC template of research, not addressing that GPC is a different material and approach it differently.

\section{Literature Review}

A study conducted by (Noushini, 2016) used three different synthesizing materials for the Geopolymer binder, a low calcium type (ASTM C 618 Class F) fly ash, Kaolite High Performance Ash (HPA) ultra-fine ash, and ground granulated blast furnace slag (GGBFS). The failure points of AAB were brittle and showed little to no softening till rupture. The research concluded that a AAB (fly ash) mix acts brittle when cured at a higher temperature and can obtain a higher modulus of elasticity. On the other hand, The OPC when heat cured displays less brittle fracture and more ductile post-peak behavior. A regression analysis was done and the following model was proposed for the modulus of elasticity of GPC as a function of the compressive strength $f_{c m}$ :

$$
E_{c}=-11400+4712 \sqrt{f_{c m}}
$$

Where $E_{c}$ is the modulus of elasticity, and $f_{c m}$ is the mean cylinder strength

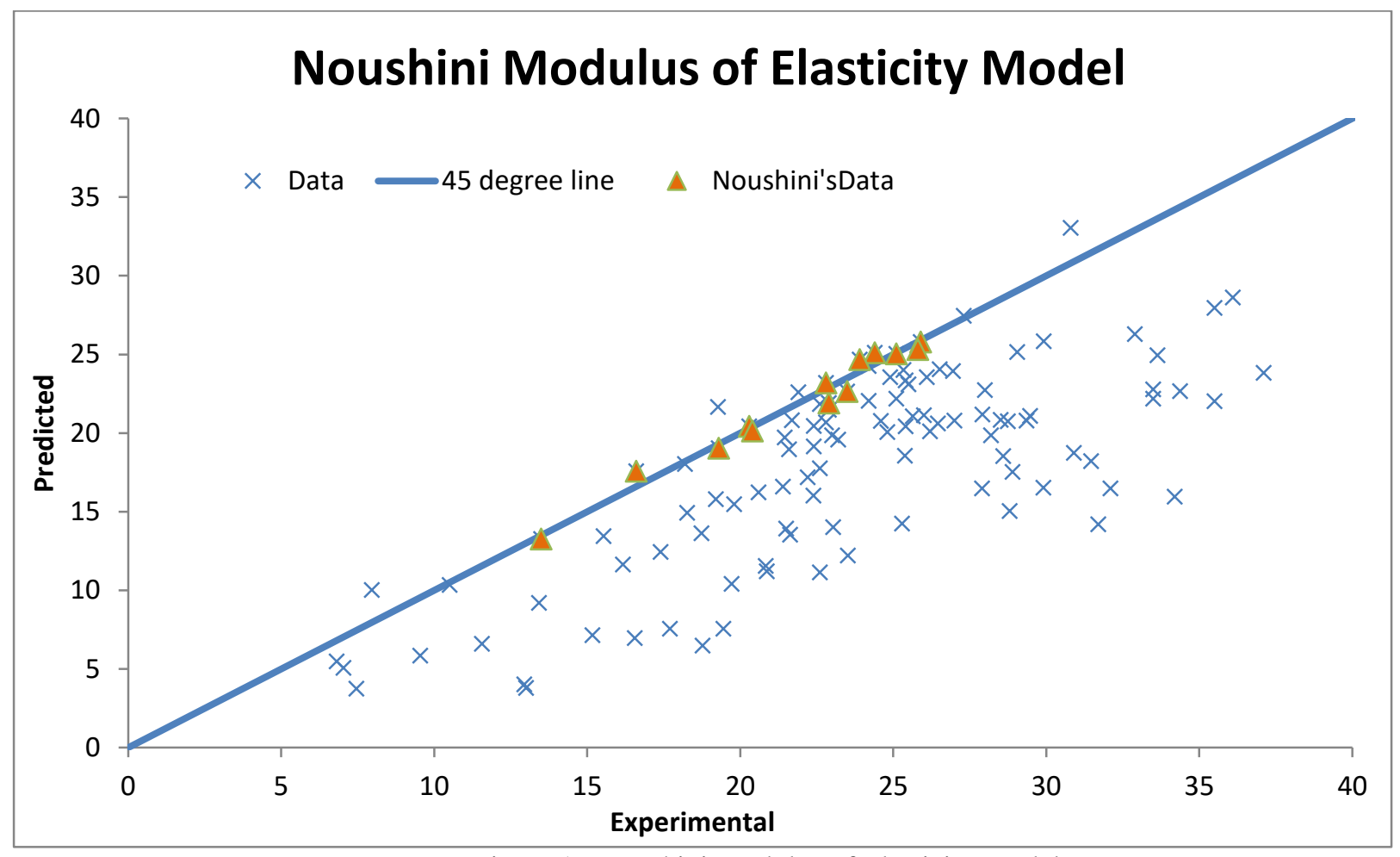

Figure 1 - Noushini Modulus of Elasticity Model

A study conducted by (Nath \& Sarker, 2017) used Class F fly ash from blast furnace slag (GGBFS), molarity used was $14 \mathrm{M}$ sodium hydroxide solution and sodium silicate. Various GGBFS and OPC percentages were used in this experiment and mixed with FA. The alkaline to fly ash ratios used were 40 and $35 \%$. The lower alkaline binder percentage improved workability of the mixture. (Nath \& Sarker, 2017)

The results obtained in this study showed that the samples gained more strength over time in the ambient curing conditions after the 28 days. The 28 days tests showed results that vary between 25 MPA to 46 MPA, while the results 
after 90 days showed strength values between 33 to 53 MPA. The results of the 28 days test increased by including GGBFS, OPC and $\mathrm{CH}$ (calcium hydroxide) to the fly ash mix. The mixes that contained less alkaline percentage to achieve a higher workability developed lower strength results; this was common even in OPC mixes when increasing the W/C ratio. After proceeding with regression to the obtained data, the following model was provided for the flexural strength $f_{c t . f}$ :

$$
f_{c t . f}=0.93 \sqrt{f_{c m}}
$$

Where $f_{c m}$ is the mean cylinder strength, and $f_{c t . f}$ is the flexural strength.

This equation presents a higher value (about 17\%) than AS 3600-2009. The results of the modulus of elasticity showed an increase when the compressive strength increased, however it was less than the OPC results and the AS 3600-2009 (21.6$31.1 \%$ ), where in other studies (Olivia \& Nikraz, 2012) when heat curing was used the results were (14.9-28.8\%) less. The following model was introduced in this study:

$$
E_{c j . a}=3510 \sqrt{f_{c}^{\prime}}
$$

Where $E_{c j . a}$ is the Modulus of Elasticity, $f_{c}^{\prime}$ is the compressive strength.

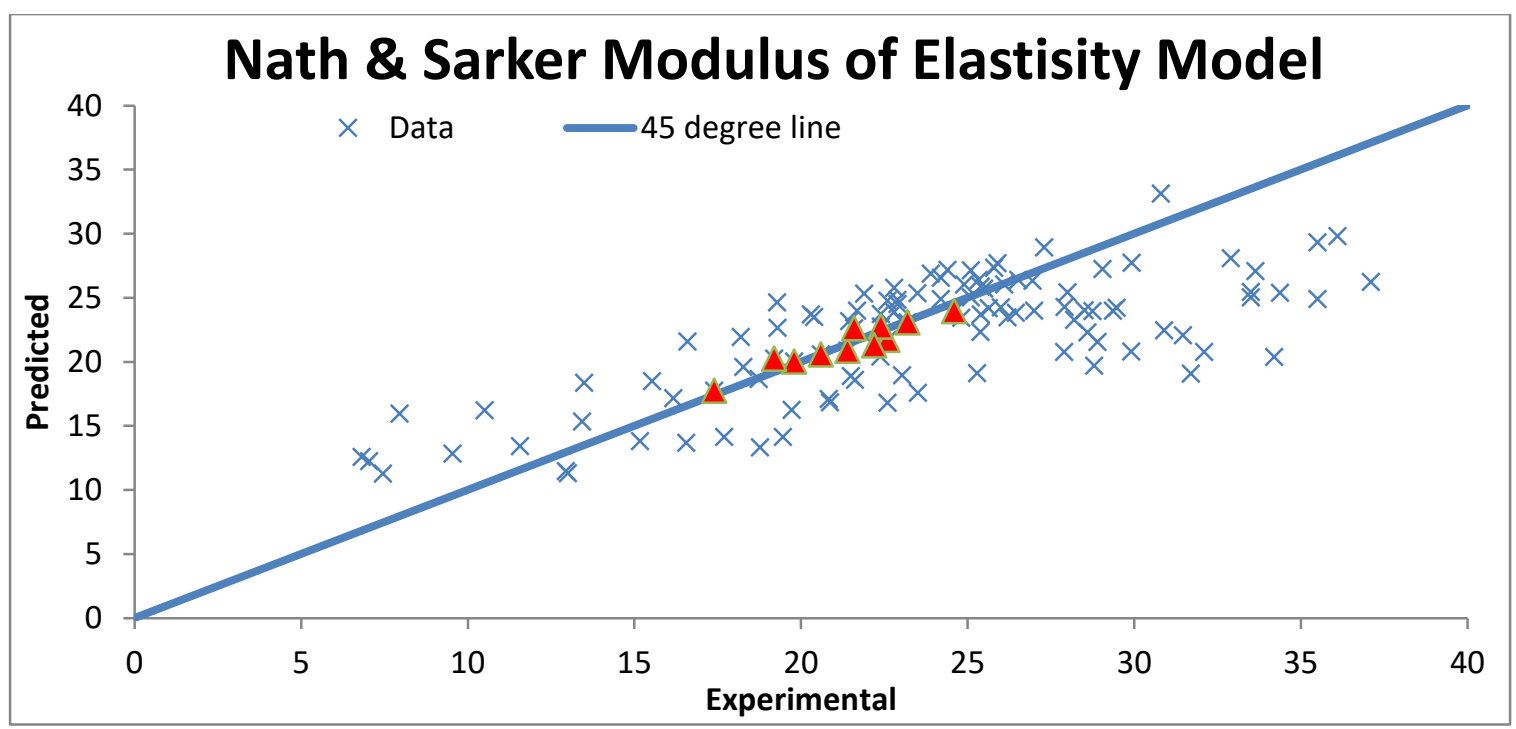

Figure 2 - Nath \& Sarker Modulus of Elasticity Model

After looking at these researches, and their outcomes, a conclusion could be drawn that there are variables that might have an effect on the proposed models. Sample size and components of the research varies among the papers. The methods and approaches to this study will be similar to what has been done previously, but on a larger samples scale and taking into consideration the testing conditions and chemical composition of the mixes.

\section{Research Methodology}

There will be some steps in order to conclude this study. The first part of it will be collecting a large set of data to ensure comprehensive results.

Analysis of the data will be done by regression and dimensional analysis. IBM SPSS statistics and MATLAB will be used to analyze the data.

The steps of this study will be:

- Collecting a large set of data points.

- Analyzing the collected data. 
- Using regression and dimensional analysis to generate models for $E_{c}, f_{r}$, and $f_{t}$.

- Test the generated models against the available data.

All the research previously uses $f_{c}^{\prime}$ to describe the mechanical properties $\left(E_{c}, f_{r}\right.$, and $\left.f_{t}\right)$ of GPC, not addressing parameters related to the testing conditions factor, and the chemical composition. Many parameters were taken as data that could potentially be affecting the model to fit that data. The following list (Table-1) concludes the parameters set data collected:

Table - 1: Factors and Components of Geopolymer Concrete Models.

\begin{tabular}{|c|c|}
\hline - Density & - Iron oxide, $\mathrm{Fe} 2 \mathrm{O} 3 \%$ \\
\hline - Curing Temperature & - $\quad$ Calcium oxide, $\mathrm{CaO} \%$ \\
\hline - $\quad$ Duration of Curing & - $\quad$ Potassium oxide, $\mathrm{K} 2 \mathrm{O} \%$ \\
\hline - Molarity & - $\quad$ Sodium oxide, $\mathrm{Na} 2 \mathrm{O} \%$ \\
\hline - Ingredients (FA, Portland, GGBFS) & - $\quad$ Magnesium oxide, $\mathrm{MgO} \%$ \\
\hline - $\quad$ Alkali liquid/fly ash \% & - Titanium oxide, $\mathrm{TiO} 2 \%$ \\
\hline - $\quad$ Silicon dioxide, $\mathrm{SiO} 2 \%$ & - $\quad$ Phosphorus oxide, P2O5\% \\
\hline - $\quad$ Aluminum oxide, $\mathrm{A} 12 \mathrm{O} 3 \%$ & - $\quad$ Sulphur trioxide, $\mathrm{SO} 3 \%$ \\
\hline
\end{tabular}

\section{Data Analysis}

In order to proceed with proposing models to describe the behaviour of Geopolymer concrete, a survey of research papers was done, and a set of data points were collected for $\left(E_{c}, f_{r}\right.$, and $\left.f_{t}\right)$ After an initial analysis was done when comparing the models presented in some of these researches, there was no one model that can fit all the data by other researchers. This lead to further inspection to the conditions of each research and more data were collected.

Each research has a unique condition that the experiment was done according to. This could possibly explain why each research has a unique model that can describe and fit their own data but not data from other research. The following plots in Fig. 3 show how the data collected fit in various models, and the best fit curve generated by excel for these data:

\section{Regression Results and Discussion}

After analysing all the collected data, a matrix of size $500 \times 33$ with 16500 data points was created. Using Table 1; the factors were divided into two categories: chemical composition and test conditions.

The test conditions include density, curing temperature, duration of curing, age of testing, alkali/FA ratio, and molarity. The chemical factor includes all the variable chemical components in the mix used in the production of GPC. Many statistical techniques were used to determine the significance of each factor in relation to dimensional reduction in order to produce two factors A and B to be used in the models; where A is a testing conditions factor, and B is a chemical composition factor. The reason behind choosing these tow descriptions for these factors is to make it easier to set boundaries or an approximation range for each class of FA chosen and assign it to a fixed value for A and B in future studies. 


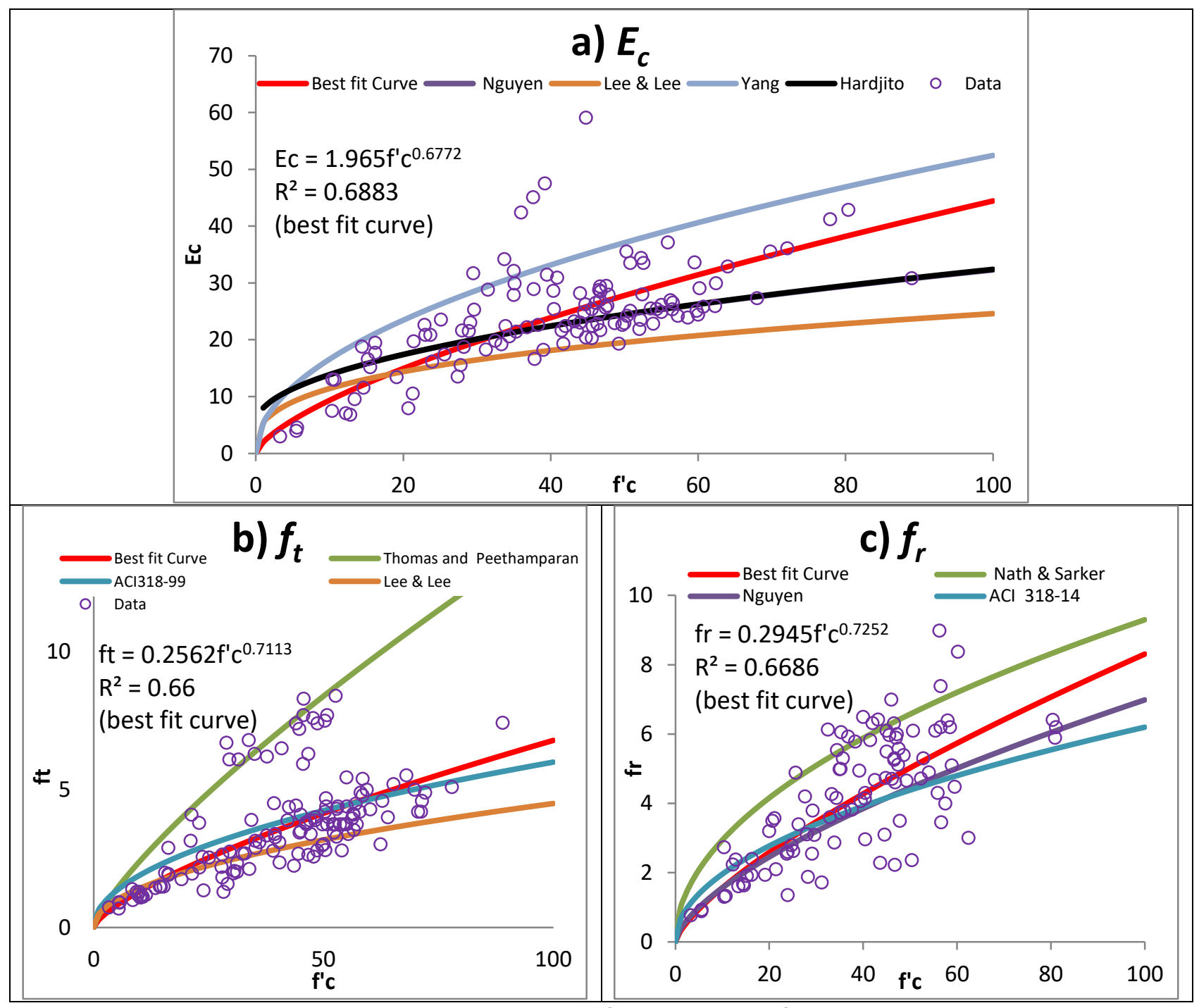

Figure $3-$ a) $E_{C}$ Models, b) $f_{t}$ Models, and c) $f r$ Models

Principal component method was used in dimensional reduction, a series of tests were performed on the factors to eliminate the unnecessary elements with low significance such as the scree plot of factors against the Eigen values (above 1), Varimax rotation was used, a forced extraction of one component to ensure a simple model. The results of the initial tests gave a $P$ value of significance of 0 , which mean the reduction of the chosen values is statistically significant. KMO test gave a value above 0.5 which means a reduction of the selected factors can be done. The process of elimination of unnecessary factors was done by analysing the component matrix table (values above 0.4) and the communalities for each factor (values above 0.6).

After obtaining the factor reduction component (A or B), a linear regression analysis was done to that component as the dependant, and the factors chosen to be reduced to generate that component as the independents. The results of this regression were for $\mathrm{A}$ and $\mathrm{B}$ in equations 4 and 5 respectively:

$$
\begin{aligned}
A= & 0.032 \times \text { Duration of curing }-0.093 \times \text { molarity of the soulution }+3.246 \\
& \times(\text { alkaline tofly ash ratio })+0.002 \times \text { temperature of curing }
\end{aligned}
$$


Where duration of curing is measured in Hours and the Temperature is in Celsius

$$
B=-0.06 \times \mathrm{CaO}+0.011 \times \mathrm{SiO} 2+0.014 \times \mathrm{Al} 2 \mathrm{O} 3-0.62 \times \mathrm{SO} 3+0.007 \times \mathrm{Fe} 2 \mathrm{O} 3
$$

Where values in this equation are in a percentage form; i.e. $\mathrm{CaO}=10$ if $\mathrm{CaO}$ percentage in the $\mathrm{FA}$ is $10 \%$.

Taking the values of $\mathrm{A}$ and $\mathrm{B}$ in including them in the regression models for $E_{C}, f r$ and $f t$ generated the following models in equations 1,2 and 3 respectively:

$$
\begin{array}{ll}
E_{C}=3.834 \sqrt{f_{c}^{\prime}}+3.00 A, & \mathrm{R}^{2}=0.954 \\
f r=0.753 \sqrt{f_{c}^{\prime}}-0.325 A, & \mathrm{R}^{2}=0.937 \\
f t=0.547 \sqrt{f_{c}^{\prime}}-0.207 B, & \mathrm{R}^{2}=0.965
\end{array}
$$

Where $\mathrm{A}$ is a function of testing conditions and $\mathrm{B}$ is a function of the chemical composition of the mix.

The value of the factors A (Testing conditions) and B (Chemical composition) varies amongst the collected data when calculated using equations 4 and 5, when observing the range of these values; A has a range between -2 and 3 , while the range of $\mathrm{B}$ is between -3.5 to 1.5 . This indicates that for the same value of the compressive strength, it is possible to have multiple values of the mechanical properties $\left(E_{C}, f r\right.$ and $f t$ ). Figures $4 \mathrm{~b}, 4 \mathrm{~d}$ and $4 \mathrm{f}$ show the upper and lower boundaries possible for the mechanical properties.

The modulus of elasticity models of (Yang, Cho, \& Song, 2012) and (Noushini et al., 2016) are examples of how the testing conditions in equation (4) could affect the model. While (Noushini et al., 2016) model is approximately matches the lower boundary of the proposed model in equation (6), (Yang et al., 2012) model curves closer to the upper boundary of the proposed model in equation (6).

Regarding the modulus of rupture, (Nath \& Sarker, 2017) model tends to match the higher boundary of the proposed model in this paper in equation (7), this could be attributed to relatively higher alkaline-FA ratio they used in their research (0.4) and higher molarity of the mix (14M) as equation (4) of the testing conditions (A) is mostly affected by these factors.

(Nguyen et al., 2016) model tends to match the lower boundary of the proposed model for modulus of rupture in this paper in equation (7), compared to (Nath \& Sarker, 2017), the molarity of the mix in (8M) instead of (14M) and the alkaline-FA ratio is also lower (0.37).

The splitting tensile strength model in (Yang, Song, \& Lee, 2010) research was lower than the lowest boundary of the proposed model in equation (8), this could be attributed to the high Coliseum $(\mathrm{CaO})$ content in their FA mix that affects the value of the factor B (chemical composition). However, the ACI318-99 model falls well between the boundaries of the proposed model in equation (8). 

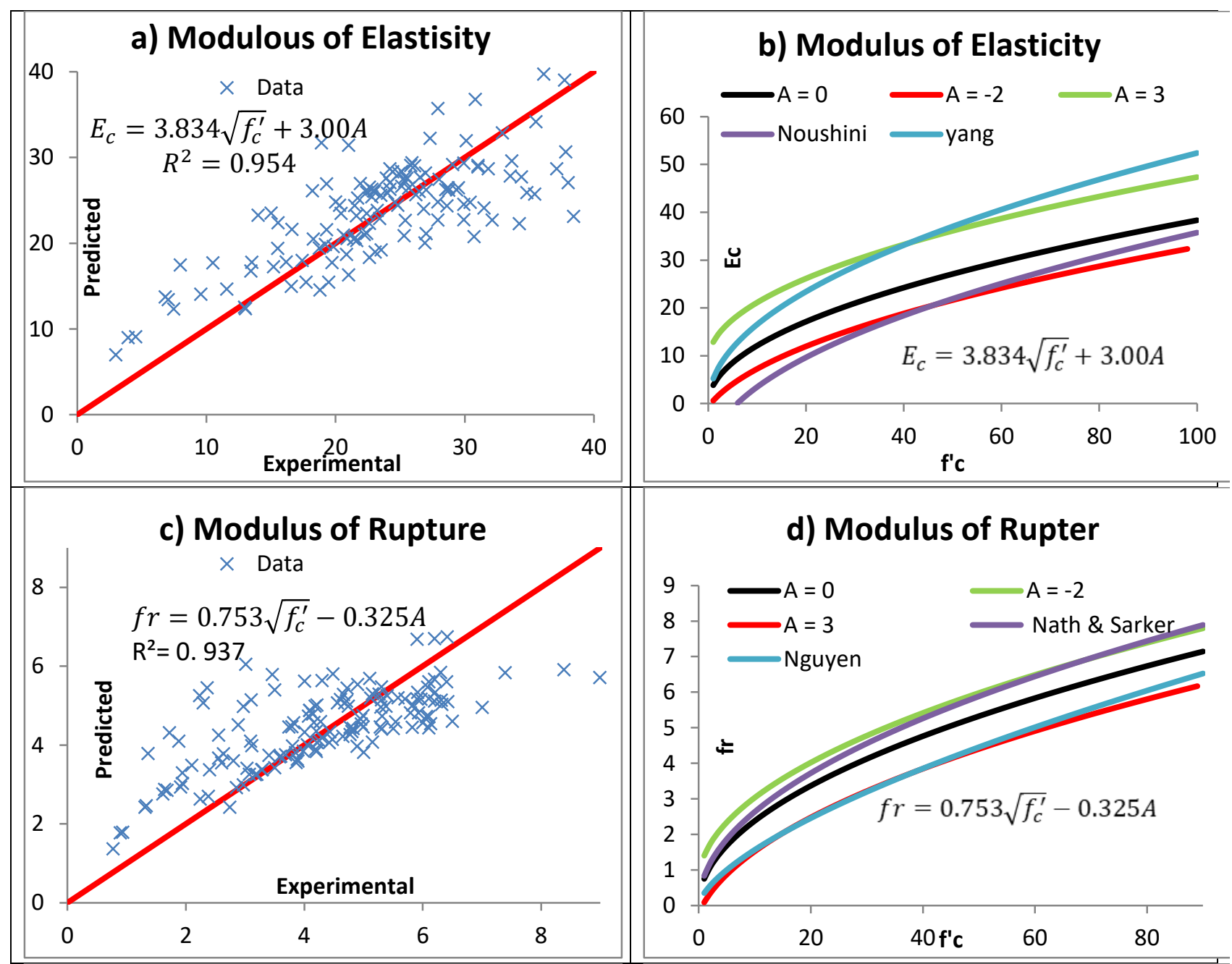

\section{d) Modulus of Rupter}
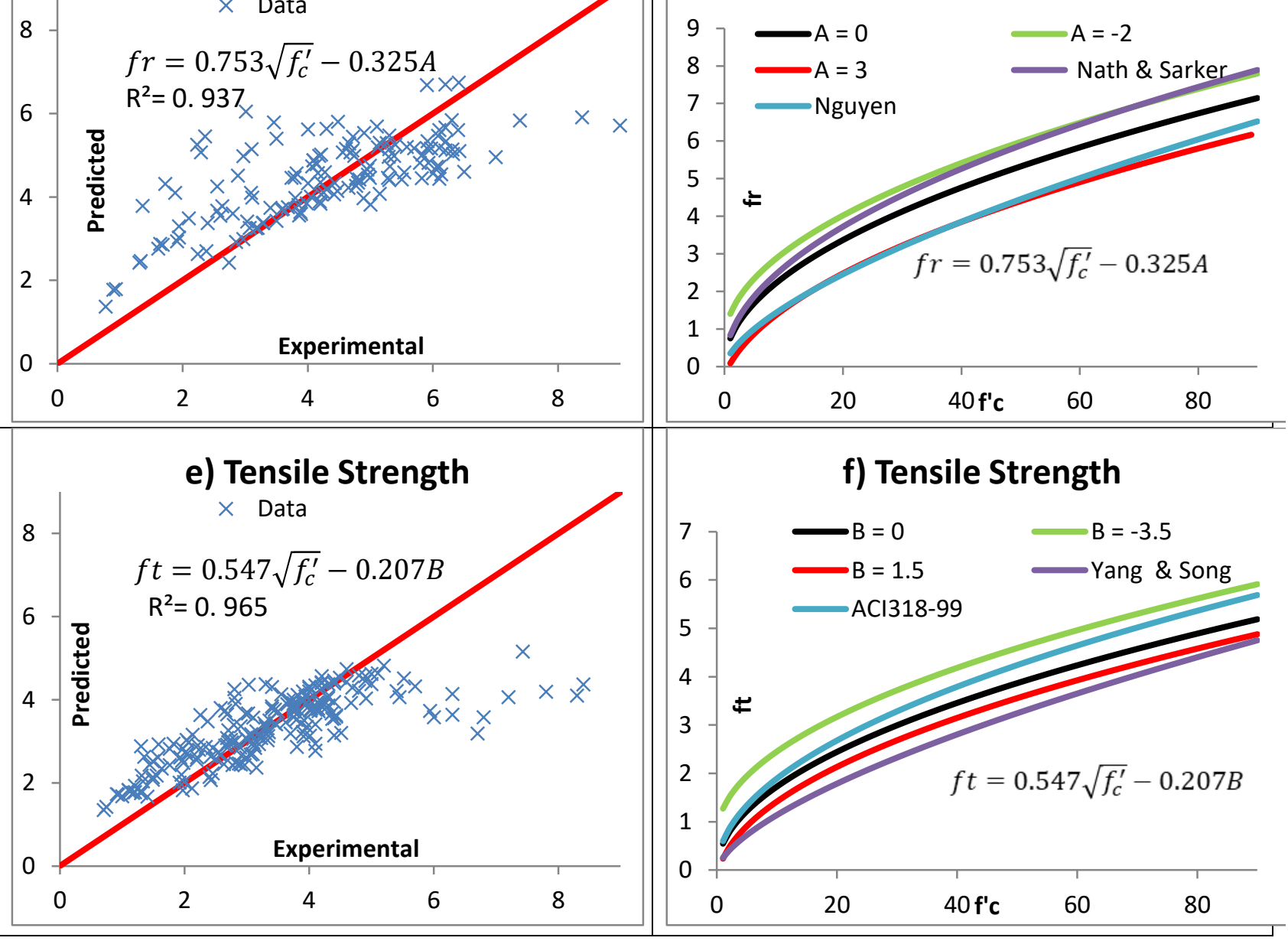

Figure 4 - Prediction Accuracy of the Proposed Models for $E_{C}, f r, f t, f r$ 


\section{Conclusion}

Despite many research done on the topic of Geopolymer concrete, unified models for the modulus of elasticity, strength and modulus of rupture are not yet present. This is what this study is attempting to provide by collecting a large of data and analysing it to propose general models to predict the mechanical properties of Geopolymer concrete. Looking the Geopolymer concrete from a different angle than OPC, by including the testing conditions and the chemical in the proposed models. After preforming a statistical analysis on the data collected, new models were proposed for the mechanical properties of Geopolymer concrete. Further research is required to support the proposed models and the inclusion of testing conditions and chemical properties when describing the mechanical properties of Geopolymer concrete.

\section{References}

[1] Mccaffrey, R. (2002). Climate change and the cement industry. Global Cement and Lime Magazine (Environmental Special Issue), 15, 19.

[2] Nath, P., \& Sarker, P. K. (2017). Flexural strength and elastic modulus of ambient-cured blended lowcalcium fly ash geopolymer concrete. Construction and Building Materials, 130, $22-31$. https://doi.org/10.1016/J.CONBUILDMAT.2016.11.034

[3] Nguyen, K. T., Ahn, N., Le, T. A., \& Lee, K. (2016). Theoretical and experimental study on mechanical properties and flexural strength of fly ash-geopolymer concrete. Construction and Building Materials, 106, 65-77. https://doi.org/10.1016/J.CONBUILDMAT.2015.12.033

[4] Noushini, A., Aslani, F., Castel, A., Gilbert, R. I., Uy, B., \& Foster, S. (2016). Compressive stress-strain model for low-calcium fly ash-based geopolymer and heat-cured Portland cement concrete. Cement and Concrete Composites, 73, 136-146. https://doi.org/10.1016/J.CEMCONCOMP.2016.07.004

[5] Olivia, M., \& Nikraz, H. (2012). Properties of fly ash geopolymer concrete designed by Taguchi method. Materials \& Design (1980-2015), 36, 191-198. https://doi.org/10.1016/J.MATDES.2011.10.036

[6] Rangan, B. V. (2007). Concrete Construction Engineering Handbook (2nd ed.; D. E. G., ed.). Perth,.

[7] Talha Junaid, M, Kayali, O., Khennane, A., \& Black, J. (2015). A mix design procedure for low calcium alkali activated fly ash-based concretes. Construction and Building Materials, 79, 301-310. https://doi.org/https://doi.org/10.1016/j.conbuildmat.2015.01.048

[8] Talha Junaid, Muhammad, Khennane, A., \& Kayali, O. (2014). Investigation into the Effect of the Duration of Exposure on the Behaviour of GPC at Elevated Temperatures. MATEC Web of Conferences, 11. Retrieved from https://doi.org/10.1051/matecconf/20141101003

[9] Yang, K.-H., Cho, A.-R., \& Song, J.-K. (2012). Effect of water-binder ratio on the mechanical properties of calcium hydroxide-based alkali-activated slag concrete. Construction and Building Materials, 29, 504511. https://doi.org/10.1016/J.CONBUILDMAT.2011.10.062

[10] Yang, K.-H., Song, J.-K., \& Lee, J.-S. (2010). Properties of alkali-activated mortar and concrete using lightweight aggregates. Materials and Structures, 43(3), 403-416. https://doi.org/10.1617/s11527-0099499-6

[11] Lee, N. K., \& Lee, H. K. (2013). Setting and mechanical properties of alkali-activated fly ash/slag concrete manufactured at room temperature. Construction and Building Materials, 47, 1201-1209. https://doi.org/10.1016/J.CONBUILDMAT.2013.05.107 